\title{
Transversalidade de gênero em política pública
}

\author{
Mariana Mazzini Marcondes' (iD 0000-0003-0701-6630 \\ Marta Ferreira Santos Farah ${ }^{2}$ (iD 0000-0002-6517-3004 \\ 'Universidade Federal do Rio Grande do Norte, Centro de Ciências Sociais Aplicadas, \\ Departamento de Administração Pública e Gestão Social, Natal, RN, Brasil. 59078-900 \\ 2Fundação Getulio Vargas, Escola de Administração de Empresas de São Paulo, \\ Departamento de Gestão Pública, São Paulo, SP, Brasil. 01332-000
}

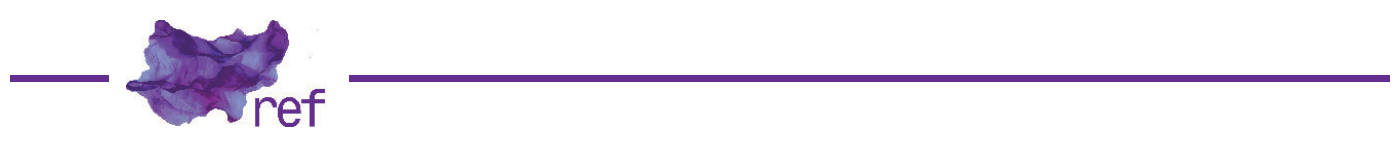

Resumo: Análises de políticas de igualdade de gênero habitam as fronteiras entre dois campos do conhecimento científico: estudos feministas e política pública. Buscando convergir as contribuições desses dois campos, debatemos o conceito de transversalidade de gênero em política pública neste ensaio teórico. Para isso, estabelecemos conexões entre eles e o conceito de enquadramento de política pública. Como resultado, definimos transversalidade de gênero como um processo de incorporação de perspectivas feministas no enquadramento de políticas públicas, tanto na construção do problema público, quanto na definição do curso da ação pública. Identificamos que esse processo se materializa no desenvolvimento de condições institucionais, propiciando a aderência das políticas às agendas políticas feministas.

Palavras-chave: transversalidade de gênero; enquadramento; estudos feministas; política pública.

\section{Gender Mainstreaming in Public Policy}

Abstract: Analyzes of gender equality policies inhabit the boundaries between two fields of scientific knowledge: feminist and public policy studies. Aiming to integrate the contributions of these two fields, this theoretical essay discusses the concept of mainstreaming gender in public policy by connecting gender mainstreaming and policy framing analysis. As a result, we define gender mainstreaming as a process of integrating feminist perspectives into the policy frame, both in the construction of the public problem and in the definition of the course of public action. This process materializes in the development of institutional conditions, fostering the adherence of policies to the feminist political agendas.

Keywords: Gender Mainstreaming; Frame; Gender Studies; Public Policy.

\section{Introdução}

Análises de políticas de igualdade de gênero habitam as fronteiras entre dois campos do conhecimento científico: o de gênero e o de política pública.

Os estudos feministas' orientam-se pelo objetivo de, a partir da produção de conhecimentos críticos e propositivos, contribuir para desnaturalizar diferenças e opressões de gênero, atribuindoIhes conteúdo social e político, o que as tornam passíveis de mudanças (Joan SCOTT, 1995; Marlise MATOS, 2008; Danièle KERGOAT, 2009). A ação pública é permeada por relações de gênero, podendo contribuir tanto para estabelecer e legitimar relações de desigualdades, quanto para transformá-las. Por conseguinte, a política pública é um objeto relevante para esse campo.

' Neste artigo, utilizamos estudos de gênero e feministas como sinônimos, assim como empregamos, frequentemente, igualdade de gênero e feminismo de forma intercambiável. 
O campo de política pública, ${ }^{2}$ por sua vez, constituiu-se, em seus primórdios, para produzir conhecimento científico, de base racional, para subsidiar a ação estatal, sobretudo as práticas governamentais, com ênfase no processo decisório (Ana Cláudia CAPELLA, 2015; Peter JOHN, 2003; Marta FARAH, 2016). Posteriormente, ampliou-se sua abrangência. Primeiramente, pelo enfoque em outras dimensões do processo de política pública, para além do processo decisório, a exemplo dos estudos de implementação. E, ainda, pela inclusão de atores (e atrizes) não governamentais no processo de produção e disseminação de conhecimento sobre políticas, resultando na emergência de novas abordagens analíticas (Carlos FARIA, 2003; FARAH, 2016).

Uma tendência do campo de política pública, que despontou nesse processo de ampliação de abrangência, foi a análise da influência das ideias em políticas públicas (JOHN, 2003; FARIA, 2003). Dentre essas análises, aquelas que enfatizam a importância das relações de poder e de dominação propiciam uma nova oportunidade de convergência com os estudos de gênero, para além de outros caminhos já explorados.

Contribuições entre estudos de gênero e de política pública não são uma novidade. Entretanto, iniciativas estruturadas de integração dos dois campos ocorreram apenas a partir da década de 1990, segundo Stephanie Paterson e Francesca Scala (2015). Nessa convergência, uma multiplicidade de abordagens teórico-metodológicas emergiu, tendo como denominador comum a atenção às conexões entre ações públicas e relações sociais de gênero.

No Brasil, Farah et al. (2018) argumentam que a integração dos referenciais dos estudos feministas e de política pública ainda é um universo a ser explorado. Prevalece, nas análises que tangenciam os dois campos, a mobilização de conceitos dos estudos de gênero para investigar políticas públicas, enquanto uma categoria empírica, com escassa utilização de conceitos e teorias desse campo. Compartilhando do diagnóstico dessas autoras, buscamos, neste artigo, subsidiar o desenvolvimento de instrumentais teóricos para análise de políticas de igualdade de gênero, integrando conceitos dos dois campos. ${ }^{3}$

Para tanto, elaboramos uma proposta de abordagem conceitual de transversalidade de gênero em política pública. Nela, articulamos reflexões feministas sobre esse conceito (Carol BACCHI, 2005; Lourdes BANDEIRA, 2005; Sylvia WALBY, 2005; Virginia GUZMÁN; Sonia MONTAÑO, 2012; Fernanda PAPA, 2012; Mariana MARCONDES; Ana Paula DINIZ; FARAH, 2018) com análises de enquadramento de política pública (policy frame analysis) ${ }^{4}$ (Martin REIN; Donald SCHÖN, 1993; Frank FISCHER, 2003; Martin LODGE, 2007; Frank BAUMGARTNER; Suzanna DE BOEF; Amber BOYDSTUN, 2008; Mary HAWKESWORTH, 2012).

No âmbito dos estudos de gênero, há esforços semelhantes de convergência (BACCHI, 2005; Mieke VERLOO; Emanuela LOMBARDO, 2007; PATERSON; SCALA, 2015). Este artigo soma-se a esses esforços, com o intuito de contribuir para adensar tais mediações. Ainda que ele seja um ensaio teórico, ilustramos sua aplicação, por meio de exemplos extraídos da política de creches brasileira (Fúlvia ROSEMBERG, 1984; Ana Paula TATAGIBA, 2011). A escolha dessa política justifica-se por ser ela uma iniciativa emblemática dos esforços de integração de uma perspectiva feminista a políticas públicas, vez que a política de creches é, recorrentemente, compreendida como um direito das crianças, e não como uma medida que também contribui para a igualdade de gênero.

Este artigo está dividido em quatro seções, incluindo esta introdução. Na segunda delas, abordamos os referenciais teóricos dos estudos de política pública, destacando as conexões com os discursos e as ideologias, e, nesse contexto, apresentamos um conceito-chave para o nosso arcabouço teórico, o de enquadramento (frame).

Na terceira seção, reestruturamos o arcabouço teórico de política pública, a partir dos aportes dos estudos de gênero. Para isso, primeiramente, explicitamos nossos pontos de partida nesse campo e, a partir deles, construímos nossa abordagem conceitual da transversalidade de gênero, convergindo contribuições dos dois campos. A transversalidade de gênero é definida como um processo específico de estruturação de políticas de igualdade de gênero. Nele, há a incorporação de perspectivas feministas no enquadramento de política pública, tanto na construção de problemas públicos, quanto na definição do curso da ação pública, materializando-se no desenvolvimento de condições institucionais para a transversalidade, que favorecem a aderência dessas políticas às agendas políticas feministas.

Por fim, a quarta parte é dedicada às conclusões, nas quais apresentamos uma síntese do trajeto percorrido e das principais contribuições do artigo, além de indicar algumas das limitações dessa reflexão teórica.

\footnotetext{
${ }_{2}$ Optamos por utilizar o termo campo de política pública, por ter ele conteúdo mais amplo do que estudos de política pública.

${ }_{3}$ Este artigo é um desdobramento de pesquisa de doutorado intitulada "Transversalidade de gênero em políticas de cuidado: uma análise comparada das políticas de cuidado infantil no Brasil, Argentina e Uruguai durante o giro à esquerda", orientada pela professora Marta Ferreira Santos Farah. Uma versão preliminar foi apresentada no VIII Encontro de Administração Pública da ANPAD (EnAPG), integrando seus anais.

${ }^{4}$ Ainda que seja recorrente nos estudos de política pública o uso do termo em inglês (frame), optamos por uma de suas possíveis traduções (enquadramento).
} 


\section{Enquadramento de política pública Virada argumentativa nos estudos de política pública}

Em suas origens, o campo de política pública enfocou o desenvolvimento de conhecimento técnico para subsidiar as práticas governamentais, com ênfase nos processos decisórios (CAPELLA, 2015; JOHN, 2003), o que se configurou em um mainstream do campo (FARIA, 2003). Posteriormente, suas fronteiras foram ampliadas, tanto pelo enfoque em outras dimensões do processo de política pública, quanto pela emergência de novas abordagens (FARAH, 2016).

Nesse contexto, investigações acerca da influência de ideias e conhecimentos sobre políticas públicas tornaram-se uma tendência contemporânea (JOHN, 2003; FARIA, 2003). Múltiplas designações surgiram para nomear as diferentes contribuições que despontaram, a exemplo de estudos cognitivos (Pierre MULLER, 2000), interpretativistas (Hendrik WAGENAAR, 2011), virada argumentativa (FISCHER; John FORESTER, 1993; FISCHER; Herbert GOTTWEIS, 2012) e institucionalismo discursivo (Vivien SCHMIDT, 2008). Em comum, essas abordagens apontam que todos os sujeitos que integram a realidade social mobilizam ideias ao agirem e interagirem, e que essa é uma dinâmica (re)configuradora de políticas públicas.

Dentre essas abordagens, há um conjunto que se aproxima mais do mainstream dos estudos de política pública e outro que propõe uma ruptura mais profunda com os pressupostos epistemológicos, ontológicos e teórico-metodológicos desse mainstream, por identificá-lo com o positivismo (JOHN, 2003; FARIA, 2003). ${ }^{5}$ Nesse segundo grupo é que se inscreve a virada argumentativa (FISCHER; FORESTER, 1993; FISCHER; GOTTWEIS, 2012), com a qual prioritariamente travamos nosso diálogo.

A virada argumentativa combinou elementos da virada linguística da filosofia ocidental, impulsionada pela Escola de Frankfurt, e, assim, incorporou contribuições de estudos da linguagem, a exemplo da Análise do Discurso (AD) (FISCHER; FORESTER, 1993). As reflexões que se inscrevem nela compartilham o intento de compreender os processos de estruturação e de análise de políticas públicas como essencialmente argumentativos, tomando a linguagem não como um instrumento neutro, mas como um sistema de significação que constitui e é constituído por relações de poder e de dominação (FISCHER; GOTTWEIS, 2012). Em seu horizonte, projetouse uma pluralidade de caminhos teóricos e metodológicos, a exemplo de análises de discurso, retórica, narrativas ou enquadramentos (REIN; SCHÖN, 1993; FISCHER, 2003; WAGENAAR, 2011).

Dentre essas abordagens inscritas na virada argumentativa, interessa-nos, neste artigo, a análise de enquadramentos de política pública, em sua interface com as contribuições da $A D$ acerca de discursos e ideologias. Assim, para que possamos construir a definição de enquadramentos é necessário, anteriormente, explicitarmos as conexões entre política pública, discurso e ideologia.

\section{Política pública, discursos e ideologias}

A AD pode ser compreendida como uma disciplina, um método ou um movimento que integra um conjunto de métodos (Fernanda MUSSALIM, 2004; Teun VAN DIJK, 1998). Seu objeto é a palavra em circulação, o que transborda a função descritiva da linguagem; o que é comunicado (Eni ORLANDI, 2000). A finalidade da AD é interpretar efeitos de sentido produzidos na interação entre sujeitos, mediados pela língua, relacionando texto e contexto histórico. Dessa forma, relações de poder são desnaturalizadas e conexões entre eventos cotidianos e estruturas sociais são evidenciadas. Nesse sentido, compreendemos por discurso as interações contextuais de sujeitos que, por meio da linguagem (falada e escrita), (re)constroem representações de mundo, (re)produzindo efeitos de sentido (Norman FAIRCLOUGH, 1989; ORLANDI, 2000).

Essas representações de mundo são permeadas por ideologias, termo que encerra múltiplas (in)definições e até mesmo estigmas (FAIRCLOUGH, 1989; John THOMPSON, 1990; Terry EAGLETON, 1991; VAN DIJK, 1998; FISCHER, 2003). Neste artigo, entendemos por ideologia um padrão de significação articulador de um conjunto de ideias socialmente compartilhadas, e individualmente apropriadas, que fundamenta discursos, tanto para estabelecer e sustentar relações de poder e de dominação, quanto para contestar, resistir e transformar essas relações. Ela não existe em abstrato (EAGLETON, 1991); ao contrário, a ideologia ganha concretude com o discurso, que não apenas a reproduz mas, dialeticamente, a transforma. Discurso e ideologia são, portanto, conceitos imbricados (FISCHER, 2003).

Discursos que mobilizam ideologias inscrevem-se em contextos históricos (Mary Jane SPINK; Maria da Gloria GIMENES, 1994; Dominique MAINGUENEAU, 2015). Esses contextos são estruturas socioculturais e, também, políticas e institucionais. A agência de sujeitos é estruturada por esses contextos, mas também os transforma, em uma dinâmica dialética entre estrutura e agência, mediada por práticas sociais. Com base em Fairclough (1989) e Spink e Gimenes (1994), podemos

${ }_{5}$ Não é objeto deste artigo um inventário exaustivo das classificações sobre estudos das ideias em política pública. Para isso, remetemos as referências mencionadas. 
entender essas práticas como linguísticas e não linguísticas, remetendo a uma área específica da vida social e possuindo certa estabilidade no tempo. É por meio delas que sujeitos, mobilizando discursos e ideologias, produzem realidades sociais.

Em face desse arcabouço teórico, entendemos as políticas públicas como um curso da ação pública, que responde a problemas públicos (FARAH, 2016), e cuja constituição é permeada por discursos e ideologias mobilizadas por sujeitos, em suas disputas e alianças. As ideologias mobilizadas nesse processo servem tanto para estabelecer e legitimar relações de dominação, quanto para contestá-las e transformá-las.

Para dar concretude a esses conceitos, lançamos mão de um exemplo, retomando o caso da educação. À medida que esse tema se constitui em um problema público, políticas são estruturadas para responder a eles. É o caso da política de creches para a educação e o cuidado de crianças de zero a três anos (ROSEMBERG, 1984; TATAGIBA, 2011). A construção do problema e a definição do curso da ação pública são delineadas por ideologias e discursos. No caso das creches, sua construção discursiva, a partir de ideologias familistas e maternalistas, pode resultar em uma política que enfoque apenas o desenvolvimento sociocognitivo das crianças, ofertandose o serviço em jornadas parciais, por supor que o cuidado deve ser realizado principalmente pelas famílias (e, dentro delas, pelas mulheres).

Alternativamente, uma política de creches que leve em conta a problemática da divisão sexual do trabalho e se comprometa com a promoção da autonomia econômica das mulheres pode ser construída a partir de um discurso feminista. É o caso de propostas de jornadas integrais ou flexíveis, que se adéquem às necessidades de quem cuida no âmbito familiar gozar de tempo livre para se dedicar a outras atividades, que não apenas o cuidar.

É a partir dessa compreensão do conceito de política pública que delineamos o que entendemos por enquadramentos.

\section{Análise de enquadramentos de política pública}

Em suas origens, a definição de enquadramentos (frames) esteve enraizada na sociologia de Goffman (Mário ALVES, 2014), que os compreendia como quadros interpretativos; esquemas que, ao mesmo tempo, permitem a construção de uma representação da realidade social e viabilizam a ação de sujeitos no mundo. Posteriormente, a análise de enquadramentos disseminouse por diferentes campos, a exemplo dos estudos de movimentos sociais (David SNOW et al. 1986; Myra FERREE; David MERRILL, 2000; Angela ALONSO; Valeriano COSTA; Débora MACIEL, 2007).

Nos estudos de política pública, a análise de enquadramentos visa a acessar valores, expectativas e crenças, subjacentes a políticas públicas (REIN; SCHÖN, 1993; MULLER, 2000; LODGE, 2007; BAUMGARTNER; DE BOEF; BOYDSTUN, 2008). São empregados para a investigação de uma multiplicidade de políticas, a exemplo da política penal (BAUMGARTNER; DE BOEF; BOYDSTUN, 2008)، antitabagista (PATERSON; SCALA, 2015) e de igualdade de gênero (VERLOO; LOMBARDO, 2007).

Nos primeiros esforços de incorporação do conceito ao campo de política pública, ele foi definido como perspectivas ou pontos de vista para organizar, interpretar e conferir sentido a uma realidade complexa, fornecendo uma diretriz para compreender os problemas públicos e incidir sobre eles (REIN; SCHÖN, 1993; HAWKESWORTH, 2012). Para William Gamson e André Modigliani (1989), enquadramentos são pacotes interpretativos, contextualmente situados, que são ativados na construção de significados de políticas, por meio de competições e alianças. Assim, eles envolvem criação, compartilhamento e mobilização de significados, inscritos em estruturas sociais e forjados nas interações comunicacionais de sujeitos (de forma consciente e inconsciente) (BACCHI, 2005; ALVES, 2014).

Segundo inventário de Kathrin Braun (2015), há uma diversidade de abordagens para a análise de enquadramentos nos estudos de política pública. Dentre elas, há aquelas que articulam enquadramentos e ideologias, que é a que utilizamos neste artigo. Nesse sentido, definimos enquadramento como narrativas estruturadas acerca de problemas públicos e do curso da ação pública, que mobilizam padrões de significação ideológicos, conferindo coerência a agendas políticas. Os enquadramentos fundamentam interações contextuais entre sujeitos, em uma dinâmica de disputas e alianças, para que haja aderência de políticas públicas a essas agendas, podendo tanto contribuir para estabelecer e legitimar relações de poder e de dominação, quanto para contestá-las e transformá-las.

Essas narrativas estruturadas envolvem um diagnóstico sobre como os sujeitos percebem o "ser" do problema público, ou seja, suas causas, quem o causa e quem é prejudicado por ele. E, também, expressam um determinado prognóstico para a ação pública, de caráter normativo, que reflete uma proposta de qual "deveria ser" a ação pública para solucioná-lo, como operacionalizá-la, quem é responsável por ela, além de qual é a realidade que se projeta como ideal, uma vez superado o problema (SNOW et al., 1986; John CAMPBELL, 2005; BACCHI, 2005; LOMBARDO; Petra MEIER, 2006). 
As agendas políticas dão concretude a essas narrativas. Elas abrangem um rol de questões identificadas como problemas públicos e propostas de soluções para resolvê-los. Esse conceito de agenda política compartilha elementos teóricos consagrados no campo de política pública (Roger COBB; Charles ELDER, 1983; John KINGDON, 2006). Entretanto, seus contornos não são sequenciais e lógicos, tampouco aleatórios. A dinâmica de sua constituição é dialética e não linear, além de integrativa das "etapas" da política pública (agenda, formulação, implementação etc.) (WAGENAAR, 2011 ; Marlon BARBEHÖN; Sybille MÜNCH; Wolfram LAMPING, 2015).

Ademais, diagnóstico e prognóstico resultam em um nó dificilmente desatável; é esperado que quem atue para definir problemas também proponha soluções. É, inclusive, recorrente que um problema seja expresso em termos de soluções (ex.: falta de creches) (Mario FUKS, 2000; Thomas BIRKLAND, 2007). Por fim, essas agendas incluem tanto as iniciativas que incidem diretamente sobre esses problemas (como a oferta de serviços públicos, diretos ou conveniados), quanto atividades de regulamentação, que definem padrões de intervenção para outras instituições (ex. creches privadas).

Para ilustrar, podemos recorrer ao que poderia ser designado como uma agenda política feminista para a políitica de creches. Nela, há diagnósticos sobre o problema público (ex.: falta de vagas em creches inviabiliza que mulheres tenham tempo livre para se inserir no mercado de trabalho ou em outras atividades para além do cuidar). Há, também, prognósticos sobre qual deveria ser a ação pública (ex.: oferta de creches públicas e de qualidade em período integral e jornada flexível). O que confere coerência e articula ambos - problema e solução; diagnóstico e prognóstico - é uma narrativa estruturada (ex.: a falta de serviços públicos de cuidado infantil contribui para a desigualdade de gênero no mundo do trabalho; o Estado deve garantir medidas de promoção da autonomia econômica das mulheres, que o tornem corresponsável pelo cuidado).

A estruturação de uma agenda política comporta nuances; ela pode compartilhar um enquadramento mais geral, mas também divergências. É possível que algumas atrizes feministas defendam as creches como um direito prioritário das mulheres que trabalham de forma remunerada, enquanto outras entendem as creches como um direito de todas as mulheres e homens que cuidam, assim como um direito das crianças.

As políticas públicas podem ter ou não aderência a agendas políticas feministas (FARAH, 2004). Políticas públicas ancoradas em enquadramentos que estabelecem e legitimam relações de dominação tendem a promover narrativas opacas, que ocultam os mecanismos de dominação, confundindo-se com o senso comum (FAIRCLOUGH, 1989; SPINK; GIMENES, 1994). Agendas políticas dominantes cristalizam-se no curso da ação pública (BARBEHÖN; MÜNCH; LAMPING, 2015), e, assim, seus enquadramentos passam a permear legados institucionais, históricos e culturais, gerando um efeito de aprisionamento dos padrões de significação do presente pelos do passado. No exemplo da política de creches, a ação pública subsidiária da responsabilidade das famílias pelo cuidado é um efeito das ideologias familistas e maternalistas, sedimentadas historicamente no senso comum das políticas sociais brasileiras.

Por outro lado, a aderência a agendas políticas que contestam essas relações de dominação pode levar à mudança no curso da ação pública. No exemplo das creches, isso pode ocorrer com a eleição de um governo que se comprometa a ampliar e reestruturar essa política, em consonância com as reivindicações feministas. Nessa dinâmica de aderência, o conteúdo dessas agendas e os padrões de significação ideológico desses enquadramentos podem ser transformados (FUKS, 2000), inclusive para minorar contradições com políticas existentes ou, ainda, com agendas políticas defendidas por outros sujeitos. Políticas de creches podem ser reformuladas para atender tanto às demandas de movimentos feministas, quanto de movimentos que advogam por direitos das crianças. Contradições e heterogeneidades permeiam esse processo, em que o Estado se constitui em múltiplas arenas (BIRKLAND, 2007; Kimberly MORGAN; Ann ORLOFF, 2017), podendo envolver diferenças entre, por exemplo, a agenda da educação e da assistência social. Ou, ainda, entre a ação governamental e a prestação judicial, como nos casos de judicialização da demanda de acesso à vaga de creches.

Na hipótese de aderência às agendas políticas (dominantes ou contestatórias), condições institucionais podem desenvolver-se, para a estruturação de direitos e implantação de políticas. Isso se dá, por exemplo, pela aprovação de um marco regulatório, criação de um ministério ou definição de um plano de ação com orçamento. Nesse caso, as condições institucionais e a aderência à agenda política são os elementos que conferem materialidade à incorporação do enquadramento na construção do problema público e na definição do curso da ação pública.

Esses processos de (re)definição de enquadramento não flutuam no ar. Eles se inscrevem na dinâmica contextual de alianças e disputas entre sujeitos (individuais e coletivos) (Maarten HAJER, 1993). Em outras palavras, o enquadramento (frame) é indissociável do processo de enquadrar (framing). Nesse, podem emergir comunidades discursivas, em torno de agendas políticas, congregando sujeitos que compartilham determinados enquadramentos e agendas políticas, disputando com outras comunidades discursivas com suas próprias agendas (HAJER, 
1993; LODGE, 2007; SCHMIDT, 2008). ${ }^{6}$ As comunidades discursivas não apenas se constituem em torno dessas agendas, mas também participam ativamente da construção delas.

As comunidades discursivas podem abarcar membros de governos, partidos, academia, movimentos sociais e empresariais, entre outros. Ainda que elas possam ser coesas, não são homogêneas, havendo controvérsias em seu interior (GAMSON; MODIGLIANI, 1989). Consequentemente, ainda que essas comunidades possam compartilhar um mesmo enquadramento e defender a mesma agenda, em suas entranhas pode haver fraturas e dissensos. No caso das creches, pode surgir uma ampla comunidade discursiva de reivindicação dessa política enquanto um direito, envolvendo membros de movimentos sociais, academia, governos, organismos internacionais e sindicatos. Mas, em seu interior, pode haver sujeitos que a reivindicam como um direito das mulheres ao trabalho, e outros sujeitos que a defendem como um direito da criança à educação.

É esperado que comunidades discursivas sejam mais bem-sucedidas à medida que construam o que denominamos, a partir de Snow et al. (1986), de um macroenquadramento. ${ }^{7}$ Ele opera como um enquadramento de larga escala, que constitui mediações entre mais de um frame (ALVES, 2014). Isso confere um padrão de significação abrangente para a aglutinação de sujeitos e seus pontos de vista (CAMPBELL, 2005; ALONSO; COSTA; MACIEL, 2007). As creches, compreendidas como um direito interdependente de quem cuida e de quem é cuidado, podem se constituir em um macroenquadramento, abarcando tanto perspectivas feministas, quanto de defesa do direito das crianças.

Essas interações estão inscritas em contextos socioculturais e político-institucionais, que propiciam condições para legitimar determinados enquadramentos, garantindo-lhes maior ressonância, ou seja, maior reverberação entre sujeitos, e até mesmo na sociedade como um todo (GAMSON; MODILIANI, 1989; SNOW et al., 1986; HAJER, 1993; SCHMIDT, 2008). Enquadramentos cujo padrão de significação seja permeado por ideologias dominantes tendem a se aproximar mais do senso comum e, assim, soarem como mais familiares. É o caso de uma política de creches que, assumindo o familismo e o maternalismo como pressuposto, afirme que as jornadas de prestação de serviços precisam ser reduzidas para garantir que o cuidado das crianças seja realizado pelas famílias e, principalmente, pelas mães, pois elas estariam mais bem cuidadas dessa forma.

Em contrapartida, enquadramentos que ativam perspectivas contestadoras tendem a soar como dissonantes. Por isso, sujeitos que os defendam devam também incidir sobre os contextos, renegociando discursivamente seus termos. A argumentação de atrizes feministas em relação a políticas de creches pode apontar que o contexto político e institucional brasileiro já prevê condições para a implantação dessas medidas, remetendo ao previsto na Constituição Federal de 1988 (CF-88). Os contextos nos quais sujeitos interagem são, portanto, produtores e legitimadores dos padrões de significação, mas eles também podem ser reconstruídos. É possível, por exemplo, que a eleição de um partido de esquerda seja narrada como um momento favorável para a ampliação da oferta de creches, em uma perspectiva feminista, mesmo que esse compromisso não tenha sido efetivamente assumido durante as eleições.

\section{Transversalidade de gênero: uma abordagem conceitual Estudos feministas: nossos pontos de partida}

As teorias feministas caracterizam-se pela produção e disseminação de conhecimentos críticos e propositivos que questionam as relações de gênero (Donna HARAWAY, 2004; Marlise MATOS, 2008). Segundo Joan Scott (1995, p. 21), "gênero é um elemento constitutivo de relações sociais, baseado nas diferenças percebidas entre os sexos". As desigualdades de gênero operam por meio da naturalização de diferenças socialmente construídas, como se as diferenças anatômicas e biológicas pudessem determinar os mais variados atributos sociais e as múltiplas trajetórias de vida. Abarcam, dessa forma, desde expressões da sexualidade e do desejo, até a inserção no mercado de trabalho e em espaços de poder.

Gênero não apenas é constitutivo de outras relações sociais (como as de classe e raça), mas ele próprio se constitui em uma relação social. Isso significa, nos termos propostos por Kergoat (2010, p. 94), tomá-lo como "uma relação antagônica entre dois grupos sociais, instaurada em torno de uma disputa (enjeu). É uma relação de produção material e ideal". Para a autora, as relações de gênero, dotadas de alto nível de abstração, possuem uma base material: a divisão sexual do trabalho (KERGOAT, 2009). Com base em Kergoat (2009), entendemos a divisão sexual do trabalho como uma forma de divisão social do trabalho, baseada nas relações de gênero, que se caracteriza pela separação e hierarquização dos espaços produtivos e reprodutivos. Os

\footnotetext{
${ }^{6}$ Existem múltiplas denominações, a exemplo de coalizões discursivas, comunidades interpretativas e comunidades discursivas. Neste artigo, entendemos todas como sinônimos.

${ }^{7} \mathrm{O}$ termo utilizado pelos autores é master frame.
} 
espaços produtivos, mais valorizados, são socialmente construídos como lócus masculino e os espaços reprodutivos, menos valorizados, como feminino. ${ }^{8}$

A divisão sexual do trabalho modificou-se nos últimos cinquenta anos, com a consolidação da presença de mulheres no mercado de trabalho, em sua diversidade de classe, raça e etnia. Importante observar que isso não significa que mulheres não estivessem inseridas no mercado de trabalho anteriormente, o que não se pode afirmar acerca das mulheres negras e empobrecidas, ainda que as ocupações que elas exerciam fossem (e em alguma medida continuem sendo) marcadas pela precariedade (ex.: trabalhadoras domésticas, quituteiras, prostitutas, entre outras profissões).

Essas mudanças não significaram, entretanto, reorganização de responsabilidades pela reprodução da vida humana. Isso sugere que as relações de gênero não apenas possuem uma base material, mas também são permeadas por ideologias. Com isso, a despeito das mudanças ocorridas na divisão sexual do trabalho, as fronteiras entre esferas pública e doméstica seguem organizando o mundo do trabalho e, por conseguinte, suas práticas sociais (FAIRCLOUGH, 1989; SPINK; GIMENES, 1994). É o que leva Helena Hirata e Kergoat (2007, p. 597) a concluírem que, nas novas configurações da divisão sexual do trabalho, "tudo muda, mas nada muda".

Relações de gênero, divisão sexual do trabalho e interações cotidianas integram-se em uma totalidade contraditória, cuja dinâmica não é mecânica ou homogênea, mas é mediada por práticas sociais (FAIRCLOUGH, 1989; SPINK; GIMENES, 1994). É por meio dessas práticas que sujeitos se inscrevem nessas relações, mas também agem e interagem sobre elas, tanto para mantê-las, quanto para transformá-las, incidindo sobre sua materialidade e sobre as ideologias que as permeiam (HIRATA; KERGOAT, 1994). Nesses termos, as críticas e proposições dos estudos feministas contribuem para compreender a realidade social e para incidir sobre esta.

Estudos feministas não apenas contribuem por meio da crítica transformativa da realidade social. Eles também enfocam a própria construção do conhecimento científico sobre essa realidade, questionando suas bases hegemônicas e impulsionando mudanças na Ciência (Sandra HARDING, 1993; MATOS, 2008). Assim, os estudos de gênero não apenas introduziram novos temas nas agendas de pesquisa de diversos campos do conhecimento. As epistemologias feministas também propuseram uma ruptura com o fazer científico, gerando instabilidades em métodos e categorias consolidadas, fundantes do positivismo científico. Assim, agregaram outras perspectivas críticas, valorizando a complexidade, a subjetividade, a reflexividade, os saberes práticos e a compreensão das relações de poder que demarcam os lugares de fala dos sujeitos.

Essa dupla crítica dos estudos feministas (à realidade social e à forma de se fazer ciência) não se limita às relações de gênero. Sobretudo nas últimas décadas, e com especial contribuição das feministas negras, evidenciou-se a intersecção das relações de gênero com outras relações sociais, como as de raça e classe (Audre LORDE, 1984; bell hooks, 2000\%; Kimberlé CRENSHAW, 2002; HIRATA, 2014; Patricia Hill COLLINS, 2015). Nos termos propostos por Collins (2015), a interseccionalidade não se limita a evidenciar a ocorrência de uma somatória de opressões. Tampouco se propõe à hierarquização de desigualdades, embora possa haver a primazia de uma ou mais relações em determinado tempo, lugar ou situação específica. Trata-se de compreender os mecanismos que permitem que essas relações se manifestem simultaneamente e que estejam imbricadas.

Tomando como base os referenciais dos estudos feministas, brevemente descritos nos parágrafos anteriores, é possível identificar alguns pontos de convergência entre eles e algumas abordagens dos estudos de política pública, a exemplo daquelas identificadas com a virada argumentativa. Primeiramente, em ambos, evidenciam-se esforços de crítica, mas também de transformação social, nos quais os pressupostos positivistas são refutados. Além disso, tanto os referenciais feministas como as abordagens de políticas públicas que destacam a importância das ideias e da argumentação atribuem centralidade às relações de poder e dominação, compreendidas como permeadas por disputas ideológicas e discursivas, como destacamos anteriormente. E, ainda que, em ambos os casos, a importância das estruturas seja reconhecida, a potencialidade das ações e interações de sujeitos não é negligenciada, sendo o conceito de práticas sociais uma importante esfera de mediação entre estrutura e agência (FAIRCLOUGH, 1989).

São esses denominadores comuns que nos permitem propor uma definição conceitual de transversalidade de gênero que integre contribuições dos estudos de gênero e de política pública, à qual dedicamos as próximas páginas.

\section{Incorporação de perspectivas para a igualdade de gênero no enquadramento de políticas públicas: transversalidade de gênero}

Nas últimas décadas, registram-se esforços para desenvolvimento de instrumentais teóricos e metodológicos para a análise de políticas de igualdade de gênero, que integrem contribuições

${ }^{8}$ Feminino e masculino não são entendidos, neste artigo, apenas em seu sentido heterossexual (cis), mas também em sua expressão trans.

${ }_{9}$ Mantivemos seu nome integralmente minúsculo em respeito à grafia adotada pela autora. 
do campo de política pública e dos estudos de gênero (PATERSON; ESCALA, 2015; Layla CARVALHO, 2018; Maxime FOREST; LOMBARDO, 2012). Por um lado, essa convergência propicia o adensamento dessas análises, à medida que se ampliam os repertórios teóricos e metodológicos disponíveis. Mas, por outro, também trazem desafios, decorrentes das diferenças existentes entre os dois campos. Enquanto os estudos de gênero já surgiram críticos, no campo de política pública ainda é forte a disputa entre vertentes positivistas e pós-positivistas.

Um dos caminhos possíveis de integração desses dois campos do conhecimento para a análise de políticas de igualdade de gênero é o da (re)formulação do conceito de transversalidade de gênero, compreendendo-o em termos de enquadramento de políticas públicas (BACCHI, 2005; LOMBARDO; MEIER, 2006; VERLOO, 2007). Como vimos, as análises de enquadramentos, compreendidas em suas articulações com os discursos e com as ideologias, oferecem uma lente teórica compatível com a concepção crítica e transformativa dos estudos de gênero.

A transversalidade de gênero, como compreendida nas teorias e práticas feministas latino-americanas e brasileiras (GUZMÁN, 2001; BANDEIRA, 2005; PAPA, 2012; GUZMÁN; MONTAÑO, 2012; Sophia REINACH, 2013), não é apenas uma tradução do termo gender mainstreaming, mas também uma ressignificação. O gender mainstreaming foi difundido, nos mais diversos países, principalmente a partir da IV Conferência Mundial de Mulheres (Pequim, 1995), como uma estratégia central para a (re)estruturação de políticas públicas, e também de culturas e práticas organizacionais do Estado, orientando-as pelo compromisso com a igualdade de gênero (ONU, 1995; Jo SHAW, 2002; WALBY, 2005). Sua rápida disseminação não significou, entretanto, que não tenha surgido dissensos e disputas em torno de seu delineamento conceitual (Mary DALY, 2005; CARVALHO, 2018).

No Brasil e na América Latina, a transversalidade passou a ser associada a uma forma de gestão governamental de políticas, propiciando condições institucionais para a incorporação de temas e perspectivas no curso da ação pública, a fim de reorientá-la, a exemplo das políticas para as mulheres, de igualdade racial, juventude, infância e direitos humanos (REINACH, 2013; MARCONDES; DINIZ; FARAH, 2018).

Há algumas sobreposições entre essa noção de transversalidade com outras, empregadas nos estudos de coordenação governamental em política pública. É o caso da intersetorialidade, o que leva autoras como Carla Bronzo (2007) a sugerirem seu uso intercambiável. Para Núria Cunill-Grau (2014), a intersetorialidade corresponde a uma integração não hierárquica de diversos setores, principalmente governamentais, que se colocam de acordo para trabalharem juntos, visando à solução de problemas sociais complexos. É possível argumentar que a transversalidade pode implicar a adoção de arranjos intersetoriais, mas que não necessariamente a ação intersetorial é também transversal. A adoção de uma política que busque integrar áreas de saúde e educação, por exemplo, não é transversal, necessariamente.

Tendo em vista as zonas cinzentas que demarcam as fronteiras desse conceito, é necessário explicitar o entendimento do qual partimos neste artigo. Por transversalidade de gênero em políticas públicas compreendemos um processo específico de estruturação das políticas para a igualdade de gênero (GUZMÁN, 2001; FARAH, 2004; BACCHI, 2005; BANDEIRA, 2005; WALBY, 2005; VERLOO; LOMBARDO, 2007; GUZMÁN; MONTAÑO, 2012). Nele, perspectivas feministas são incorporadas ao enquadramento dessas políticas, para construir problemas públicos e definir 0 curso da ação pública, materializando-se no desenvolvimento de condições institucionais para a aderência de políticas públicas às agendas políticas feministas.

É possível classificar nossa abordagem como tridimensional. Isso porque a transversalidade de gênero, como definimos, é composta por três dimensões imbricadas: enquadramento das políticas por perspectivas feministas; condições institucionais para a transversalidade; e aderência às agendas políticas feministas. Por estarem imbricadas, essas dimensões são indissociáveis. Entretanto, para finalidade heurística, é possível fracioná-las.

Na dimensão do enquadramento são explicitadas as disputas discursivas em torno dos significados de gênero nas políticas públicas. Já as condições institucionais e a aderência evidenciam a materialidade do processo, ou seja, os efeitos concretos que a incorporação da transversalidade produz na ação pública. Passamos, a seguir, a refletir sobre cada uma delas.

A análise do enquadramento aponta que perspectivas de gênero, interseccionadas com outras relações sociais, permeiam a construção dos problemas públicos e a definição do curso da ação pública, ainda que isso seja imperceptível (Kathy STAUDT, 2003; DALY, 2005). Com efeito, perspectivas patriarcais de gênero podem cristalizar-se em políticas públicas (BARBEHÖN; MÜNCH; LAMPING, 2015), relegando questões centrais da opressão de gênero à esfera doméstica (PATERSON; SCALA, 2015). Consequentemente, essas questões não se constituem em um problema público legítimo. É o caso da problemática do cuidado infantil, que enfrenta dificuldades para se enraizar na esfera pública como uma questão política, e não privada.

Mas não apenas pela inação o Estado reproduz desigualdades; a estruturação de políticas públicas pode ser orientada por perspectivas patriarcais, como vimos, anteriormente, na hipótese de políticas de creches que sejam enquadradas pelo familismo e maternalismo. 
Por outro lado, a incorporação de perspectivas de igualdade de gênero no enquadramento de políticas pode ser assumida como um compromisso público, orientando a mudança no padrão de significação ideológico de suas narrativas estruturadas. Nesse caso, empreende-se um esforço para romper com o congelamento de perspectivas patriarcais no senso comum das práticas governamentais, além de fomentar iniciativas para a igualdade de gênero, em articulação à igualdade de classe, raça, entre outras (STAUDT, 2003; DALY, 2005).

Trata-se de um processo que possui uma carga normativa; a transversalidade de gênero orienta-se por um princípio normativo (igualdade de gênero). Consequentemente, sua realização comporta gradações e nuances. Ademais, essa proposição normativa conflita com a orientação historicamente consolidada no curso da ação pública, comprometida com a reprodução e legitimação de desigualdades. Assim, é de se esperar que a "transversalização" de políticas seja conflituosa e não linear.

Essa abordagem permite, partindo de Shaw (2002) e Daly (2005), entender que, caso haja incorporação da transversalidade, ela pode ser integrada ou marginalizada, além de comportar gradações entre essas possibilidades. Em ambas, a transversalidade coexiste, conflituosamente, com enquadramentos cristalizados. A diferença é que, na transversalidade que denominamos de integrada, esse conflito resulta em um esforço de reorganização do curso da ação pública, orientando-se pelo objetivo da igualdade de gênero. Na marginal, esse objetivo é acoplado à dinâmica existente, sem reestruturá-la.

Ao enfatizarmos, em nossa definição, a dimensão processual da transversalidade, não a comprometemos com uma única perspectiva de igualdade de gênero (PATERSON; SCALA, 2015; STAUDT, 2003). As perspectivas feministas devem ser entendidas no plural; múltiplas são as compreensões e formas de incidência sobre as relações de gênero (BACCHI, 2005; VERLOO, 2007). Dessa forma, elas podem se restringir a mulheres, ou abarcar as relações de gênero. Também podem representar a mulher como um sujeito universal, ou interseccionado com outras relações sociais (DALY, 2005). Por fim, também pode conferir níveis diversos de legitimidade para as vozes dos movimentos feministas e de mulheres (WALBY, 2005).

Não são, contudo, todas as políticas para as mulheres que incorporam uma perspectiva de igualdade de gênero, ainda que elas possam se colocar como alinhadas a essa narrativa. Políticas para mulheres são aquelas cujas beneficiárias são mulheres; exclusivas ou prioritárias (FARAH, 2004; BANDEIRA, 2005). Elas podem reproduzir estereótipos de gênero, contribuindo para reproduzir desigualdades. Um exemplo pode ser depreendido de Tatagiba (2011), que, ao analisar a política de creches promovida pela Legião Brasileira de Assistência, aponta que elas previam a ampliação de vagas por meio de, entre outras iniciativas, o trabalho em rodízio das mães nas atividades diárias desse serviço.

Por outro lado, o enfoque em políticas para as mulheres pode configurar-se em uma estratégia para a construção da igualdade de gênero, entendendo que, ao se garantirem direitos e inclusão social das mulheres, também se modificam as relações de gênero (Luís FUJIWARA, 2002; FARAH, 2004; MARCONDES; DINIZ; FARAH, 2018). Um exemplo foi a criação de uma Secretaria de Políticas para as Mulheres (SPM) (e não de lgualdade de Gênero), no âmbito do Governo Federal brasileiro, em 2003 (CARVALHO, 2018).

A complexidade que permeia essas reflexões e as múltiplas possibilidades das perspectivas para a igualdade de gênero não inviabilizam a análise de enquadramentos de políticas públicas. Ao contrário, essa análise pode contribuir com a compreensão de nuances nas ações estatais comprometidas com a igualdade de gênero (LOMBARDO, 2008), uma vez que distintas perspectivas podem ser mobilizadas nessa "transversalização".

Como vimos anteriormente, agendas políticas dão concretude às narrativas estruturadas expressas pelos enquadramentos, enquanto estes dão coerência àquelas. Agendas políiticas de igualdade de gênero integram questões e temas priorizados acerca dos problemas de gênero e o curso da ação pública orientados por esses temas (FARAH, 2004). Políticas públicas podem ter aderência a essas agendas, em diferentes graus. À medida que isso ocorre, estruturam-se políticas de igualdade de gênero. Nesse sentido, a aderência das políticas a essas agendas feministas é um efeito da reestruturação do enquadramento em uma perspectiva de igualdade de gênero, o que the confere materialidade.

O compromisso com a transversalidade de gênero deve permear o conjunto das ações públicas, mas, como observa Staudt (2003), é necessário começar por algum lugar. Isso nos introduz à terceira e última dimensão, a das condições institucionais. Com efeito, para a efetivação da transversalidade, são necessárias instituições que estruturem esse processo no âmbito do Estado (STAUDT, 2003), a exemplo de Organismos de Políticas para as Mulheres (OPMs), como a citada SPM. Além de planos de ações envolvendo o conjunto de setores de atuação estatal, com previsão orçamentária para efetivação, e de iniciativas para a participação social na gestão da transversalidade (GUZMÁN, 2001; GUZMÁN; MONTAÑO, 2012). Com isso, criam-se condições para que a disputa do curso da ação pública seja feita. 
Ainda que essas três dimensões sejam imbricadas, elas não resultam automaticamente umas das outras. A criação de condições institucionais, por exemplo, não garante a aderência de políticas públicas às agendas políticas feministas, sendo possível que haja criação de OPMs, mas que eles não influenciem o curso das políticas (FUJIWARA, 2002; FARAH, 2004).

Por fim, se o enquadramento é indissociável do enquadrar, o processo de transversalidade de gênero deve ser considerado em relação às interações entre as atrizes, e ao contexto em que isso ocorre. Com efeito, agendas políticas feministas são mobilizadas por atrizes que, em determinados contextos, aliam-se e disputam, para garantir a aderência de políticas e a estruturação de condições institucionais. No caso da política de creches brasileira, isso ocorreu durante a elaboração da CF-88, em que movimentos feministas e de mulheres reivindicaram essa política como uma prioridade com estatuto constitucional (ROSEMBERG, 1984; TATAGIBA, 2011 ).

Essas reivindicações por creches encontraram ressonância no contexto político da redemocratização, no qual a defesa da garantia de direitos gozou de notável prestígio. Essas demandas não se limitaram a essas atrizes, mas foram compartilhadas com uma comunidade discursiva ampla, que congregava movimentos pelos direitos das crianças. Com isso, um macroenquadramento emergiu, congregando diferentes sujeitos e pontos e de vista, e se cristalizou na CF-88, garantindo-se as creches como um direito ao trabalho e à educação infantil.

\section{Conclusōes}

Neste artigo, debatemos o conceito de transversalidade de gênero em política pública, partindo das convergências do campo de política pública e estudos feministas. Para tanto, estruturamos um arcabouço teórico articulador de reflexões sobre discurso e ideologia, enquadramento e enquadrar, agenda política e comunidade discursiva. Para dar concretude ao debate teórico, lançamos mão de exemplos depreendidos da política de creches.

Definimos transversalidade de gênero como um processo de incorporação de perspectivas feministas no enquadramento de política pública, tanto na construção do problema público (diagnóstico), quanto na definição do curso da ação pública (prognóstico). Esse processo se materializa no desenvolvimento de condições institucionais, favorecendo a aderência dessas políticas às agendas políticas feministas. É o que denominamos de conceito tridimensional da transversalidade, cujas dimensões, imbricadas, podem ser fracionadas, para finalidades heurísticas.

Por meio dessa definição, esperamos contribuir com a integração de estudos de política pública e de gênero, subsidiando teorias sobre essas políticas e práticas a elas relacionadas, considerando tanto a ação pública como um todo, quanto políticas específicas. Há, contudo, algumas limitações em nossa reflexão que, em caráter de considerações finais, cabe salientar. Primeiramente, ainda que tenhamos mobilizado pontualmente o exemplo das creches para ilustrar sua aplicação, tratou-se de um "exercício" preliminar, visando a facilitar a compreensão de nossa proposta, sendo fundamental que esse arcabouço teórico seja "posto à prova" em novas pesquisas empíricas, propiciando seu desenvolvimento.

Ademais, enfocamos, neste artigo, a política pública, ainda que a transversalidade envolva outros aspectos da ação pública, como a cultura institucional, práticas organizacionais e formação de pessoal. É importante destacar, ainda, que a transversalidade de gênero não esgota o conceito de transversalidade, que também pode ser empregado para analisar outras políticas (ex.: igualdade racial, juventude e direitos humanos). E, tampouco, esgota o conceito de gênero, inclusive porque as lutas feministas transbordam os limites da política pública.

\section{Referências}

ALONSO, Angela; COSTA, Valeriano; MACIEL, Débora. "Identidade e estratégia na formação do movimento ambientalista brasileiro". Novos Estudos CEBRAP, São Paulo, n. 79, p. 151167, nov. 2007. Disponível em http://www.scielo.br/scielo.php?script=sci_arttext\&pid=S0101$33002007000300008 \& \operatorname{lng}=$ en\&nrm =iso. Acesso em 03/12/2020.

ALVES, Mário Aquino. "Social Accountability as an Innovative Frame in Civic Action: The Case of Rede Nossa São Paulo". Voluntas, Manchester, v. 25, p. 818-838, 2014.

BACCHI, Carol. "The MAGGEQ project: identifying contesting meaning of 'gender equality"'. The Greek Review of Social Research, Athens, n. 1 17, p. 221-234, 2005. Disponível em https://ejournals. epublishing.ekt.gr/index.php/ekke/article/viewFile/9564/9750.pdf. Acesso em 03/1 2/2020.

BANDEIRA, Lourdes Maria. Fortalecimento da Secretaria Especial de Políticas para as Mulheres: avançar na transversalidade da perspectiva de Gênero nas Políticas Públicas. Brasília: Comissão Econômica para a América Latina e o Caribe (Cepal); Secretaria de Políticas para as Mulheres da Presidência da República (SPM/PR), jan. 2005. Disponível em https://www.cepal.org/mujer/reuniones/ quito/Lourdes_Bandeira.pdf. Acesso em 03/12/2020. 
BARBEHÖN, Marlon; MÜNCH, Sybille; LAMPING, Wolfram. "Problem definition and agenda-setting in critical perspective". In: FISCHER, Frank et al. Handbook of critical policy studies. Cheltenham: Edward Elgar Publishing, 2015. p. 241-258.

BAUMGARTNER, Frank; DE BOEF, Suzanna; BOYDSTUN, Amber. The decline of the death penalty and the discovery of innocence. New York: Cambridge University Press, 2008.

BRAUN, Kathrin. "Between representation and narration: analysing policy frames". In: FISCHER, Frank et al. Handbook of Critical Policy Studies. Cheltenham: Edward Elgar Publishing, 2015. p. 441-461.

BRONZO, Carla. "Intersetorialidade como princípio e prática nas políticas públicas: reflexões a partir do tema do enfrentamento da pobreza". In: XII CONGRESSO DO CENTRO LATINOAMERICANO DE ADMINISTRACIÓN PARA EL DESARROLLO - CLAD, Santo Domingo. Anais... Venezuela: CLAD, 2007, [s.n.].

BIRKLAND, Thomas. "Agenda Setting in Public Policy". In: FISCHER, Frank; MILLER; Gerald J.; SIDNEY, Mara S. Handbook of public policy analysis: theory, politics, and methods. Boca Raton-Florida: CRC Press, 2007. p. 63-78.

CARVALHO, Layla Daniele Pedreira. "A SPM e as políticas para as mulheres no Brasil: saltos e sobressaltos na institucionalização das demandas das agendas feministas". In: MATOS, Marlise; ALVAREZ, Sonia E. Quem são as mulheres das políticas para mulheres no Brasil? Porto Alegre: Zouk, 2018. p. 87-138.

CAMPBELL, John. "Where do we stand? Common mechanisms in organizations and social movements research". In: DAVIS, Gerald et al. (Eds.). Social movements and organization theory. New York: Cambridge University Press, 2005, p. 41-68.

CAPELLA, Ana Cláudia Niedhardt. "Análise de políticas públicas: da técnica às ideias". Idéias, Campinas. v. 6, n. 2, p. 13-34, 2015. Disponível em https://periodicos.sbu.unicamp.br/ojs/index. php/ideias/article/view/8649461. Acesso em 03/12/2020.

COBB, Roger; ELDER, Charles. Participation in American politics: The dynamics of agenda - building 2. ed. Baltimore: The Johns Hopkins University Press, 1983.

COLLINS, Patricia Hill. "Em direção a uma nova visão: raça, classe e gênero como categorias de análise e conexão". In: MORENO, Renata (Org.). Reflexões e práticas de transformação feminista. São Paulo: SempreViva Organização Feminista (SOF), 2015. p. 13-42.

CRENSHAW, Kimberlé. "Documento para o encontro de especialistas em aspectos da discriminação racial relativos ao gênero". Revista Estudos Feministas, Florianópolis, v. 10, n. 1, 2002. p. 171-188. Disponível em http://www.scielo.br/scielo.php?script=sci arttext\&pid=S0104026X200200010001 1 \&lng=en\&nrm=iso. Acesso em 03/12/2020.

CUNILL-GRAU, Núria. "La intersetorialidad en las nuevas politicas sociales: un acercamiento analíticoconceptual". Gestión y Políticas Públicas, Ciudad de Mexico, v. 23, n. 1, p. 5-46, 2014. Disponível em http://www.scielo.org.mx/pdf/gpp/v23n1/v23n1al.pdf. Acesso em 03/12/2020.

DALY, Mary. "Gender mainstreaming in theory and practice". Social Politics: International Studies in Gender, State and Society, v. 2, n. 3. Oxford: Oxford University Press, 2005. p. 433-450. Disponível em https://academic.oup.com/sp/article/12/3/433/1679271. Acesso em 03/12/2020.

EAGLETON, Terry, Ideologia: Uma introdução. São Paulo: EDUNESP, 1991.

FARAH, Marta F. S. "Gênero e políticas públicas". Revista Estudos Feministas, Florianópolis, v. 12, n. 1, p. 47-71, abr. 2004. Disponível em http://www.scielo.br/scielo.php?script=sci arttext\&pid=S010426X2004000100004\&lng=en\&nrm=iso. Acesso em 03/12/2020.

FARAH, Marta F. S. "Análise de políticas públicas no Brasil: de uma prática não nomeada à institucionalização do 'campo de públicas'". Revista de Administração Pública, Rio de Janeiro, v. 50, n. 6, p. 959-979, dez. 2016. Disponível em http://www.scielo.br/scielo.php?script=sci arttext\&pid=S003476122016000600959\&lng=en\&nrm=iso. Acesso em 03/1 2/2020.

FARAH, Marta Ferreira Santos et al. "Gênero e política pública: panorama da produção acadêmica no Brasil (1983-2015)". Cadernos EBAPE.BR, Rio de Janeiro, v. 16, n. 3, p. 428-443, set. 2018. Disponível em http://www.scielo.br/scielo.php?script=sci_ arttext\&pid=S16793951 2018000300428\&lng=en\&nrm=iso. Acesso em 03/12/2020. 
FAIRCLOUGH, Norman. Language and power. New York: Longman, 1989.

FARIA, Carlos Aurélio Pimenta de. "Ideias, conhecimento e políticas públicas: um inventário sucinto das principais vertentes analíticas recentes". Revista Brasileira de Ciências Sociais, São Paulo, v. 18, n. 51, p. 21-30, fev. 2003. Disponível em http://www.scielo.br/scielo.php?script=sci arttext\&pid=S010269092003000100004\&lng=es\&nrm=iso. Acesso em 03/12/2020.

FERREE, Myra Marx; MERRILL, David A. "Hot Movements, Cold Cognition: Thinking about Social Movements in Gendered Frames". Contemporary Sociology, lowa, v. 29, n. 3, p. 454-462, 2000. Disponível em https://www.jstor.org/stable/2653932?seq=1. Acesso em 03/12/2020.

FISCHER, Frank; FORESTER, John (Eds.). The Argumentative Turn in Policy Analysis and Planning. Durham: Duke University Press, 1993.

FISCHER, Frank. Reframing Public Policy. Oxford: Oxford University Press, 2003.

FISCHER, Frank; GOTTWEIS, Herbert (Eds.). The Argumentative Turn Revisited: Public Policy as Communicative Practice. London: Duke University Press, 2012. p. 114-148.

FOREST, Maxime; LOMBARDO, Emanuela. The Europeanization of Gender Equality Policies: A Discursive-Sociological Approach. London: Palgrave Macmillan, 2012. p. 1-27.

FUJIWARA, Luis Mário. Governo: substantivo feminino? Gênero e políticas públicas em governos subnacionais. 2002. Dissertação (Mestrado em Administração Pública e Governo) - Escola de Administração de Empresas de São Paulo, Fundação Getulio Vargas, São Paulo, São Paulo, SP, Brasil.

FUKS, Mario. "Definição de agenda, debate público e problemas sociais: uma perspectiva argumentativa da dinâmica do conflito social". Revista Brasileira de Informação Bibliográfica em Ciências Sociais (BIB), Rio de Janeiro, n. 49, p. 79-94, 2000. Disponível em https://dspace.almg.gov. br/handle/1 1037/26475. Acesso em 03/12/2020.

GAMSON, William A.; MODIGLIANI, Andre. "Media Discourse and Public Opinion on Nuclear Power: A Constructionist Approach". American Journal of Sociology, Chicago, v. 95, n. 1, p. 1-37, 1989. Disponível em https://www.jstor.org/stable/2780405. Acesso em 03/12/2020.

GUZMÁN, Virginia. La institucionalidad de género en el Estado: nuevas perspectivas de análisis. CEPAL, Santiago de Chile, n. 32, marzo 2001. Serie Mujer y Desarrollo - CEPAL. Disponível em https:// repositorio.cepal.org/bitstream/handle/1 1362/5878/1/S01030269_es.pdf. Acesso em 03/12/2020.

GUZMÁN, Virginia; MONTAÑO, Sonia. Políticas públicas e institucionalidad de género en América Latina (1985-2010). CEPAL, Santiago de Chile, n. 118, 2012. Serie Mujer y Desarrollo - CEPAL. Disponível em https://repositorio.cepal.org/bitstream/handle/1 1362/5847/S1200803_es.pdf. Acesso em 03/12/2020.

HAJER, Maarten A. "Discourse coalitions and the institutionalization of practice: the case of acid rain in Great Britain". In: FISCHER, Frank; FORESTER, John. The argumentative turn in policy analysis and planning. London: Duke University Press, 1993. p. 43-74.

HARAWAY, Donna. "'Gênero' para um dicionário marxista: a política sexual de uma palavra". Cadernos Pagu, Campinas, n. 22, p. 201-246, 2004. Disponível em https://periodicos.sbu.unicamp. br/ojs/index.php/cadpagu/article/view/8644638. Acesso em 03/12/2020.

HARDING, Sandra. "A instabilidade das categorias analíticas na teoria feminista". Revista Estudos Feministas, Florianópolis, v. 1, n. 1, p. 7-32, 1993. Disponível em https://periodicos.ufsc.br/index.php/ ref/article/view/15984. Acesso em 03/12/2020.

HAWKESWORTH, Mary. "From policy frames to discursive politics: feminist approaches to development policy and planning in an era of globalization". In: FISCHER, Frank; GOTTWEIS, Herbert (Eds.). The argumentative turn revisited: public policy as communicative practice. London: Duke University Press, 2012. p. 114-148.

HIRATA, Helena Sumiko; KERGOAT, Danièle. "A Classe operária tem dois sexos". Revista Estudos Feministas, Florianópolis, v. 2, n. 3, p. 92-100, 1994. Disponível em https://periodicos.ufsc.br/index. php/ref/article/view/16291. Acesso em 03/12/2020.

HIRATA, Helena Sumiko; KERGOAT, Danièle. "Novas configurações da divisão sexual do trabalho". Cadernos de Pesquisa Fundação Carlos Chagas, São Paulo, v. 37, n. 132, p. 595-609, set./dez. 
2007. Disponível em https://www.scielo.br/scielo.php?pid=S0100-15742007000300005\&script=sci abstract\&tIng=pt. Acesso em 03/12/2020.

HIRATA, Helena Sumiko. "Gênero, classe e raça. Interseccionalidade e consubstancialidade das relações sociais". Tempo social, São Paulo, v. 26, n. 1, p. 61-73, June 2014. Disponível em http:// www.scielo.br/scielo.php?script=sci_arttext\&pid=S010320702014000100005\&lng=en\&nrm=iso. Acesso em 03/12/2020.

hooks, bell. Feminism is for everybody. Cambridge: South End Press, 2000.

JOHN, Peter. "Is there life afterPolicyStreams, Advocacy Coalitions, and Punctuations: Using Evolutionary Theory to Explain Policy Change?". The Policy Studies Journal, London, v. 31, n. 4, 2003. Disponível em https://onlinelibrary. wiley.com/action/showCitFormats?doi=10.1111\%2F15410072.00039. Acesso em 03/12/2020.

KERGOAT, Danièle. "Divisão sexual do trabalho e relações sociais de sexo". In: HIRATA, Helena et al. (Orgs.). Dicionário crítico do feminismo. São Paulo: EDUNESP, 2009. p. 67-75.

KERGOAT, Danièle. "Dinâmica e consubstancialidade das relações sociais". Novos Estudos - CEBRAP, São Paulo, n. 86, p. 93-103, mar. 2010. Disponível em http://www.scielo.br/scielo.php?script=sci arttext\&pid=S010133002010000100005\&lng=en\&nrm=iso. Acesso em 03/12/2020.7

KINGDON, John Wells. "Como chega a hora de uma ideia?". In: SARAVIA, Enrique; FERRAREZI, Elisabete (Orgs.). Políticas públicas: coletânea. Brasília: Escola Nacional de Administração Pública (ENAP), 2006. p. 219-225. v. 1 .

LODGE, Martin. "Comparative Public Policy". In: FISCHER, Frank; MILLER, Gerald J.; SIDNEY, Mara S. Handbook of public policy analysis: theory, politics, and methods. Boca Raton-Florida: CRC Press, 2007. p. 63-78.

LOMBARDO, Emanuela; MEIER, Petra. "Gender mainstreaming in the EU: incorporating a feminist reading?". European Journal of Women's Studies, London, v. 13, n. 2, p. 151-166, 2006. Disponível em https://journals.sagepub.com/doi/10.1177/1350506806062753. Acesso em 03/12/2020.

LORDE, Audre. "Age, race, class and sex: women redefining difference". In: LORDE, Audre. Sister outsider: essays and speeches. Berkeley: Crossing Press, 1984. p. 114-123.

MAINGUENEAU, Dominique. Gênese do discurso. São Paulo: Parábola Editorial, 2015.

MARCONDES, Mariana M.; DINIZ, Ana Paula R.; FARAH, Marta F. S. "Transversalidade de gênero: uma análise sobre os significados mobilizados na estruturação da política para mulheres no Brasil". Revista do Serviço Público, Brasília, v. 69, n. 2, p. 36-62, 2018.

MATOS, Marlise. "Teorias de gênero ou teorias e gênero? Se e como os estudos de gênero e feministas se transformaram em um campo novo para as ciências". Revista Estudos Feministas, Florianópolis, v. 16, n. 2, p. 333-357, 2008. Disponível em http://www.scielo.br/scielo.php?script=sci arttext\&pid=S0104026X2008000200003\&Ing=en\&nrm=iso. Acesso em 03/12/2020.

MORGAN, Kimberly; ORLOFF, Ann Shola. "Introduction: The many hands of the State". In: MORGAN, Kimberly; ORLOFF, Ann Shola (Orgs.). The many hands of the State. Cambridge: Cambridge University Press, 2017. p. 1-32.

MULLER, Pierre. "L'analyse cognitive des politiques publiques: vers une sociologie politique de l'action publique". Revue Française de Science Politique, Paris, v. 50, n. 2, p. 189-208, 2000.

MUSSALIM, Fernanda. "Análise do discurso". In: MUSSALIM, Fernanda; BENTES, Anna Christina. Introdução à linguística: domínios e fronteiras. São Paulo: Cortez, 2004. p. 101-139. v.2.

ONU. ORGANIZAÇÃO DAS NAÇÕES UNIDAS. Beijing Declaration and Platform for Action (The Fourth World Conference on Women). Beijing, 1995. Disponível em https://www.un.org/womenwatch/daw/ beijing/platform/. Acesso em 03/12/2020.

ORLANDI, Eni. Análise do discurso: Princípios e procedimentos. Campinas: Pontes, 2000.

PAPA, Fernanda de C. Transversalidade e políticas públicas para mulheres no Brasil: Percursos de uma pré-política. 2012. Dissertação (Mestrado em Administração Pública e Governo) - Escola de Administração de Empresas de São Paulo, Fundação Getulio Vargas, São Paulo, SP, Brasil. 
PATERSON, Stephanie; SCALA, Francesca. "Making gender visible: exploring feminist perspectives through the case of anti-smoking policy". In: FISCHER, Frank et al. Handbook of Critical Policy Studies. Cheltenham: Edward Elgar Publishing, 2015. p. 481-505.

REIN, Martin; SCHÖN, Donald. "Reframing Policy Discourse". In: FISCHER, Frank; GOTTWEIS, Herbert. The Argumentative Turn in Policy Analysis and Planning. London: Duke University Press, 1993. p. 145167.

REINACH, Sophia. Gestão transversal de políticas públicas no âmbito federal brasileiro: uma leitura inicial. 2013. Dissertação (Mestrado em Administração Pública e Governo) - Escola de Administração de Empresas de São Paulo da Fundação Getulio Vargas, São Paulo, SP, Brasil.

ROSEMBERG, Fúlvia. "O movimento de mulheres e a abertura política no Brasil: O caso da creche". Cadernos de Pesquisa, São Paulo, n. 51, p. 73-79, nov. 1984. Disponível em http://publicacoes.fcc. org.br/ojs/index.php/cp/article/view/1462. Acesso em 03/12/2020.

SCHMIDT, Vivien A. "Discursive institutionalism: the explanatory power of ideas and discourse". Annual Review of Political Science, Palo Alto, v. 11, n. 1, p. 303-326, 2008. Disponível em https://www. annualreviews.org/doi/abs/10.1 146/annurev.polisci. 11 1.060606.135342. Acesso em 03/12/2020.

SCOIT, Joan. Gênero: uma categoria útil para a análise histórica. Recife: SOS Corpo, 1995.

SHAW, Jo. "The European Union and gender mainstreaming: constitutionally embedded or comprehensively marginalised?". Feminist Legal Studies, Canterbury, Springer, v. 10, p. 213-226, 2002. Disponível em https://link.springer.com/article/10.1023/A:1021271711517. Acesso em $03 / 12 / 2020$

SNOW, David A. et al. "Frame alignment processes, micromobilization and movement participation". American Sociological Review, Chicago, v. 51, n. 4, p. 464-481, 1986. Disponível em www.jstor.org/ stable/2095581. Acesso em 03/12/2020.

SPINK, Mary Jane P.; GIMENES, Maria da Gloria G. "Práticas discursivas e produção de sentido: apontamentos metodológicos para a análise de discursos sobre a saúde e a doença". Saúde e Sociedade, São Paulo, v. 3, n. 2, p. 149-171, 1994. Disponível em https://www.scielo.br/scielo. php?script=sci_arttext\&pid=S0104-12901994000200008. Acesso em 03/12/2020.

STAUDT, Kathy. "Gender mainstreaming: conceptual link to institutional machineries", In: RAl, Shirin M. Mainstreaming gender, democratizing the State: institutional mechanisms in the advancement of women. Manchester: Manchester University Press, 2003. p. 40-65.

TATAGIBA, Ana Paula. "Percursos de uma luta urgente: educação infantil como dever do Estado". Ser Social, Brasília, v. 13, n. 29, p. 90-112, jul./dez. 2011. Disponível em https://www.scielo.br/pdf/ ensaio/v18n67/a06v1867.pdf. Acesso em 03/12/2020.

THOMPSON, John Brookshire. Ideologia e cultura moderna: teoria social crítica na era dos meios de comunicação de massa. 9. ed. Petrópolis: Vozes, 1990.

VAN DIJK, Teun. Ideology: a multidisciplinary approach. London: Sage Publications, 1998.

VERLOO, Mieke; LOMBARDO, Emanuela. "Contested gender equality and policy variety in Europe: introducing a critical frame analysis approach". In: VERLOO, Mieke (Ed.). Multiple meanings of gender equality: a critical frame analysis of gender policies in Europe. Budapest: Central European University Press, 2007. p. 21-51.

WALBY, Sylvia. "Gender Mainstreaming: Productive Tensions in Theory and Practice". Social Politics: International Studies in Gender, State \& Society, v. 12, n. 3, p. 321-343, Fall 2005. Disponível em https://academic.oup.com/sp/article-abstract/12/3/321/1679224. Acesso em 03/12/2020.

WAGENAAR, Hendrik. Meaning in Action: Interpretation and Dialogue in Policy Analysis. London: Routledge, 2011.

Mariana Mazzini Marcondes (mariana.mazzini.m@gmail.com) é professora de Administração Pública e Gestão Social da Universidade Federal do Rio Grande do Norte (UFRN). Doutora em Administração Pública e Governo da Escola de Administração de Empresas de São Paulo da Fundação Getulio Vargas (FGV/EAESP), mestra em Política Social pela Universidade de Brasília (UNB) e graduada em Direito pela Faculdade de Direito da Universidade de São Paulo (USP). 
Marta Ferreira Santos Farah (marta.farah@fgv.br) é doutora, mestra e graduada em Sociologia pela Faculdade de Filosofia, Letras e Ciências Humanas (FFLCH) da Universidade de São Paulo (USP). Professora Titular do Departamento de Gestão Pública da Escola de Administração de Empresas de São Paulo da Fundação Getulio Vargas (FGV/EAESP). Áreas de interesse: políticas públicas, políticas sociais e direitos, políticas públicas e gênero.

COMO CITAR ESSE ARTICO DE ACORDO COM AS NORMAS DA REVISTA

MARCONDES, Mariana Mazzini; FARAH, Marta Ferreira Santos. "Transversalidade de gênero em política pública". Revista Estudos Feministas, Florianópolis, v. 29, n. 1, e65398, 2021.

\section{CONTRIBUIÇĀO DE AUTORIA}

As autoras contribuíram igualmente.

\section{FINANCIAMENTO}

Este artigo foi desenvolvido a partir de tese de doutorado em Administração Pública e Governo, que contou com o apoio financeiro da Coordenação de Aperfeiçoamento de Pessoal em Nível Superior (CAPES), por meio da concessão de bolsa de doutorado (Código de Financiamento 001).

\section{CONSENTIMENTO DE USO DE IMAGEM}

Não se aplica

\section{APROVAÇĀO DE COMITÊ DE ÉTICA EM PESQUISA}

Não se aplica.

\section{CONFLITO DE INTERESSES}

Não se aplica.

\section{LICENÇA DE USO}

Este artigo está licenciado sob a Licença Creative Commons CC-BY 4.0 International. Com essa licença você pode compartilhar, adaptar, criar para qualquer fim, desde que atribua a autoria da obra.

\section{HISTÓRICO}

Recebido em 28/05/2019

Reapresentado em 13/05/2020

Aprovado em 24/07/2020

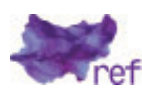

